\title{
0 conceito de ideologia no marxismo clássico: uma revisão e um modelo de aplicação
}

Adriano Codato ${ }^{1}$

\section{Resumo}

O propósito deste artigo é demonstrar alguns aspectos operacionais da noção teórica de "ideologia", tal como pensada pelo marxismo, a fim de enfatizar suas habilidades para uso prático na análise social. 0 argumento a ser defendido aqui é que, atualizado ou não com as modas acadêmicas, esse termo ainda funciona desde que compreendido no seu sentido integral. Mostro então como a transfiguração do sentido do conceito (do negativo ao positivo) e da realidade que ele descreve (de fenômeno puramente mental para estrutura material), permite entender a prática ideológica como prática social, e como tudo isso vem enredado pela noção de "tradição", tal como já pensada por Engels e Marx. Em seguida, enumero alguns pré-requisitos teóricos e metodológicos para produzir um mapa das ideologias de uma formação social. Esse mapa pode servir não apenas para descrever a topologia de um dado campo ideológico, mas para demonstrar como, quando e por que uma determinada ideologia se torna a ideologia dirigente e o seu discurso, o discurso dominante numa sociedade.

Palavras-chave: ideologia; marxismo; ideologias dirigentes; teoria social; análise social.

\section{Introdução}

O conceito de ideologia é possivelmente um dos conceitos mais controversos da Ciência Social. Abercrombie, Hill e Turner anotaram que "é amplamente aceito que a noção de 'ideologia' deu origem a mais dificuldades conceituais e analíticas do que provavelmente qualquer outro termo nas ciências sociais" (1984: 187).

Vinculado originalmente ao marxismo, seu uso foi pouco a pouco desacreditado em nome de noções concorrentes como as de "representação coletiva" (Durkheim), "derivações" (Pareto), "hegemonia" (Gramsci), "utopia" (Mannheim) "mito" (Barthes),

\footnotetext{
${ }^{1}$ Doutor em Ciência Política. Professor de Ciência Política na Universidade Federal do Paraná (UFPR). E-mail: adriano@ufpr.br.
} 
"discurso" (Pêcheux), "imaginário" (Castoriadis), "mentalidade" (Febvre), "doxa" (Bourdieu), entre muitas outras. Descontadas diferenças puramente políticas que repercutem na atividade intelectual, e que estiveram na base da "superação" do conceito de ideologia, sua recusa foi creditada à variedade e à complexidade do mundo social que aqueles termos substitutivos permitiriam melhor captar. Acrescente-se a esse prodígio dois outros lances. 0 fato de 0 conceito de ideologia ser tradicionalmente associado ao marxismo fez com que o seu sucesso científico dependesse diretamente do prestígio acadêmico e da relevância política dessa teoria social. À medida que a importância universitária do marxismo diminuiu nos últimos anos do século XX e nos primeiros do XXI (Soares, 2013), diminuiu também a capacidade heurística da noção de ideologia.

Ao lado desse feito cultural contemporâneo, é preciso considerar um segundo acontecimento "ideológico". Periodicamente se decreta a morte ou, no mínimo, "o declínio das ideologias". No final dos anos 1950, Daniel Bell publicou um livro cujo título dispensaria maiores interpretações: The End of Ideology2. Na virada para os anos 1980, os pós-modernos, vivendo eles numa sociedade "pós-industrial" e "pósclassista", decretaram que a nossa época seria também "pós-ideológica" (cf. Lyotard, 1979). O que se postulava é que como não havia, na realidade, ideologia (o fenômeno social), não precisava haver $o$ conceito teórico (o referente mental) que o designasse. Paradoxalmente, o uso do termo "ideologia" passou a ser ele mesmo ideológico (Eagleton, 1997).

0 propósito deste ensaio é relevar alguns aspectos operacionais da noção teórica de ideologia, tal como pensada pelo marxismo, a fim de enfatizar suas habilidades para uso prático na análise social. 0 argumento a ser defendido aqui é que, atualizado ou não com as modas acadêmicas, esse termo ainda funciona adequadamente - desde que compreendido na sua significação integral. É essa significação que se pretende restituir.

\section{Do falso ao verdadeiro: a trajetória histórica da noção de ideologia}

\section{a. O conceito de ideologia na teoria social}

Bendix anotou que embora diferentes concepções de ideologia fossem propostas e desenvolvidas desde que o termo entrou em

\footnotetext{
2 Esse livro é bem mais complexo e as questões que ele coloca bem mais sugestivas do que seu título sugere. E o resumo que ele contém da teoria marxista da ideologia é preciso, elegante e didático. Ver Bell, 1980: 319-326.
} 
circulação em princípios do século $\mathrm{XX}$, elas nunca deixaram de se referir ao ponto de vista fundamental de Marx sobre o assunto, elaborado em meados do XIX: "as ideias não podem nem devem ser tomadas pelo seu significado manifesto, mas analisadas em termos das 'forças' [sociais] que estão por trás delas" (Bendix, 1996: 372).

Embora incompleta, essa interpretação da teoria marxiana da ideologia contribuiu para a necessária politização do conceito, já que desloca a discussão sobre "as ideias" do terreno da Epistemologia e da Sociologia da Cultura para o terreno das práticas e dos interesses sociais. 0 foco da análise deve ser então "não o que uma pessoa diz, mas o motivo por que ela o diz" (Bendix, 1996: 372). Dito de maneira mais difícil e mais exata: a ideologia deve ser pensada como "uma função da relação de uma elocução com seu contexto social" (Eagleton, 1997: 22).

Tendo presente essa premissa, Raymond Williams recomendou que se distinguissem três versões ordinárias do conceito de ideologia: $i$ ) ideologia como um sistema de crenças característico de uma determinada classe ou grupo social; ii) ideologia como um sistema ilusório de crenças (ideias falsas ou "falsa consciência", na expressão inventada por Engels), que pode ser contrastado com o conhecimento verdadeiro ou com o conhecimento científico sobre o mundo social; e iii) ideologia como resultado do processo coletivo de produção de ideias e significados na vida social (Williams, 1977: 55).

Geuss ponderou que o primeiro item resume aquilo que se poderia chamar de uma definição descritiva do conceito. 0 termo ideologia pode então ser assimilado à "visão de mundo" (ou, num registro mais politizado, à "consciência de classe"). 0 segundo item traduz a definição negativa de ideologia e, nessa acepção, há duas variantes: $a$ ) cognitiva (ligada à veracidade ou falsidade das ideias); e $b$ ) política (ideias que, embora "falsas" por si mesmas, ajudam a legitimar e garantir a dominação social). 0 último item dá um significado positivo ou pragmático à ideia de ideologia e ela pode ser assimilada à noção de "cultura" em um sentido muito próximo, mas não idêntico, ao antropológico: uma maneira de os indivíduos orientarem-se e orientar socialmente suas práticas (Geuss, 1981, apud Eagleton, 1997 p. 49-50; p. 38).

Bobbio (2002) contrapôs uma definição mais neutra e mais operacional à acepção negativa do termo e à sua função mistificadora (encontrável tanto em Marx como em Pareto, lembra ele). "Ideologia" poderia então significar, também, "um sistema de crenças ou de valores, que é utilizado na luta política para influir no comportamento das massas, para orientá-las em uma direção em vez de outra, para 
obter o consenso, enfim, para instituir a legitimidade do poder". Nesse nível de generalidade, "uma teoria política qualquer" ou uma doutrina "pode tornar-se ideologia no momento em que vem assumida como programa de ação de um movimento político" (Bobbio, 2002: 129). Pense-se aqui, por exemplo, na afinidade entre a teoria do autoritarismo brasileiro (Oliveira Vianna, Francisco Campos, Azevedo Amaral, etc.) e as realizações do regime do Estado Novo ${ }^{3}$.

Esquema 1. Sentidos possíveis do termo "ideologia"

\begin{tabular}{llc}
\hline definição descritiva & sistema de crenças & visões de mundo \\
\hline definição negativa & $\begin{array}{l}\text { sistema ilusório de } \\
\text { crenças }\end{array}$ & ideias falsas \\
\hline definição performativa & $\begin{array}{l}\text { processo social de } \\
\text { produção de ideias }\end{array}$ & idéias legítimas \\
\hline
\end{tabular}

Fonte: o autor

A história do conceito de ideologia resumida a seguir demonstra em que ordem cada uma dessas variantes se firmou na escola marxista.

\section{b. O conceito marxista de ideologia}

Originalmente, "ideologia" designava, conforme a crença materialista, apenas aquilo que sua etimologia indicava: uma ciência das ideias ou o estudo científico das ideias (ide(o)- + -logia). Por oposição à metafísica, Destutt de Tracy argumentou, em fins do XVIII, em Eleménts d'idéologie, que ideias procediam das percepções sensoriais do mundo exterior, e não de raciocínios a priori, sendo elas, portanto, resultado da interação entre "organismos vivos" (os agentes sociais) e o "meio ambiente" (o mundo social). Pouco depois, quatro outros significados bastante diferentes desse primeiro surgiram e emprestaram ao termo uma conotação crítica e negativa que o acompanharia até hoje.

Bonaparte reprovou a atividade política dos "ideólogos" e registrou que a ação reformadora do círculo de colaboradores do Institut Nationale (do qual fazia parte de Tracy), inspirada nos ideais do Iluminismo, consistia, de fato, na capacidade para manipular as ideias para edificar "um governo de homens sanguinários" (apud Thompson, 1995: 47). Ideologia tornou-se então, pelas mãos de Napoleão, um corpus de idéias flexível e adaptável que se prestaria a toda sorte de

3 Para uma fundamentação desse ponto, ver Silva, 2004; Losso, 2006; e Codato, 2008. 
manipulação política. Como essa má doutrina estava em desacordo com o sentimento dos homens e as lições da História, tal como o Imperador os concebia, "ideologia" passou também a nomear toda teoria abstrata, imaginativa, irrealizável na prática, num sentido muito próximo daquele dado por Gramsci à noção de "ideologias arbitrárias", por oposição a "ideologias historicamente orgânicas" (Gramsci, 1977: 1.456).

Na corrente marxista clássica, o termo ideologia foi mais frequente nos textos de polêmica política e filosófica do que no discurso teórico propriamente dito. Ele seria utilizado por Engels e Marx para qualificar pensamentos e doutrinas tomados enquanto entidades puras, independentes da realidade material, isto é, enquanto juízos puramente especulativos, tais como os sistemas de filosofia e religião. Esses sistemas teriam produzido até então "ideias falsas" sobre os homens (Marx e Engels, 1982: 1.049). Num dos exemplos escolhidos pelos autores, é como se o mundo social real, ignorado pelos teóricos profissionais, pudesse ser reduzido, graças à ação dessas fabulações ideológicas, a uma batalha imaginária de "frases contra frases" (Marx e Engels, 1982: 1.054), onde as ideias e os conceitos seriam, graças a seu poder mágico, os verdadeiros princípios determinantes da realidade. Engels, bem mais adiante, agregou outro significado à noção de ideologia sem refutar esse primeiro. Ideologia passou a compreender também todos os motivos, falsos ou aparentes, todas as concepções ilusórias que concorriam para ocultar do próprio agente social suas condições de existência e as contradições sociais em que estava enredado. Daí ideologia passar a ser sinônimo, também, de "falsa consciência" (Engels, 1979b, vol. 3: 293).

No século XX a palavra conservou, na língua comum, aquela acepção dicionarizada e neutra de "conjunto de convicções filosóficas, sociais, políticas etc. de um indivíduo ou grupo de indivíduos" (Dicionário Houaiss), mas também o termo ainda segue designando qualquer pensamento doutrinário, sectário, parcial, absoluto, dogmático- e, portanto, defeituoso - sobre o mundo. Paralelamente, o conceito desprendeu-se daquela faculdade quase natural que o impelia a nomear um conhecimento errado do mundo social, seja como filosofia especulativa (Marx e Engels), seja como consciência social falsificada (Engels) e assumiu, para os marxistas, um sentido mais descritivo (Lênin) e mais explicativo (Gramsci). Mas, em todo caso, menos pejorativo. Para Lênin, ideologia tornou-se a forma de consciência política das classes sociais ("consciência de classe"); para Gramsci, a consciência teórica ou subjetiva dos processos sociais. 
Em Lênin, 'ideologia' é o sistema ou conjunto de ideias, principalmente políticas, produto de um grupo ou classe social, que, através desse sistema, representa, manifesta, justifica e racionaliza seus interesses. Daí sua fraseologia característica: "ideologia proletária", "ideologia burguesa", "ideologia pequeno-burguesa", etc. Já em Gramsci, ideologia indica a totalidade das formas de consciência social ou, de maneira mais direta, visões e concepções de mundo dominantes transformadas em "senso comum", e que concorrem para a coesão ("cimento") social. Por ordem de complexidade, são elas: filosofia, religião, senso comum e folclore (cf. Williams, 2007: 212-217; Larrain, 1988: 183-187). Assim, as ideologias (no plural) funcionam, na teoria de Gramsci, como forças organizadoras e não como concepções intelectuais que podem ser verdadeiras ou falsas por si mesmas. São elas que, no limite, circunscrevem o espaço social onde os agentes "atuam, lutam e adquirem consciência de suas posições sociais" (Eagleton, 1997: 109).

Nesse sentido, o termo "ideologia" passa a designar não mais, ou não somente, uma figuração irreal do mundo social (na linguagem dos marxistas, figuração irreal das relações de exploração econômica) ou mesmo especulação arbitrária ("filosofia", na direção dada ao termo na Ideologia alemã). Ideologia se torna uma sorte de autoconsciência de classe, consciência essa capaz de aglutinar interesses, definir padrões de comportamento coletivo e de funcionar como um princípio gerador da congruência social.

Esse percurso, aqui resumido, permiteentão rever a concepção materialista de ideologia, não só intuindo a complexidade do problema na filosofia de Marx e dos marxistas, mas a complicação e o interesse do problema em si mesmo. Explico esses pontos todos na próxima seção, pois me parecem especialmente úteis para aqueles ainda interessados no seu emprego prático na análise social.

\section{O duende de Engels e o poder social das ideias}

Depois da virada de sentido da noção de ideologia em Lênin e em Gramsci, ainda na primeira metade do século XX, o novo conceito impôs ao marxismo uma reinterpretação da relação entre a estrutura econômica da sociedade (relações de propriedade, formas de produção, tecnologias, etc.) e as ideias provenientes das superestruturas culturais, já que essas últimas não poderiam ser definidas mais como meras derivações da primeira. Foram dois os princípios teóricos redescobertos ou reinterpretados para admitir, a partir de então, a função positiva da ideologia: i) o mundo social deve ser pensado in 
totum, e não mais a partir das relações, das mediações ou das oposições entre seus níveis (conforme o esquema simplificado que justapõe base+ superestrutura); e ii) as estruturas ou níveis do todo social têm eficácia própria, isto é, poder para produzir efeitos reais.

É assim que já nos anos 1930 Gramsci e depois na sua linha Raymond Williams, nos anos 1970, irão vindicar para uma teoria materialista da ideologia (termo que preferem abandonar, substituindo-o por "hegemonia", no primeiro caso, e "cultura", no segundo) o estatuto do ideológico como criador e produtor da realidade social e não como instância reprodutora de significados e valores dominantes, simplesmente.

A intuição original dessa ideia pode ser lida já no próprio Marx e também em Engels. Segundo a interpretação de Gramsci,

a proposição contida na Introdução [no Prefácio] de Para a crítica da Economia Política, que os homens tomam consciência dos conflitos estruturais [ou seja, dos conflitos fundamentais de uma sociedade] no terreno das ideologias, deve ser considerada como uma afirmação do valor gnosiológico e não puramente psicológico e moral das concepções de mundo (Gramsci, 1978: 57; grifado no original; acréscimos entre colchetes meus).

Voltarei a esse ponto (o valor gnosiológico das ideologias) adiante. Por ora quero considerar rapidamente a fonte dessa ideia a partir da sugestão do autor dos Quaderni.

Ideologia(s) deve(m) ser vista(s) não como "ideias", mas como "formas ideológicas". O que isso significa e qual a importância dessa variação que não é meramente terminológica?

No Prefácio da Crítica da Economia Política de 1859 lê-se que:

A mudança da base econômica [de uma sociedade] é acompanhada de uma transformação mais ou menos rápida em todo este enorme edifício [social]. Quando se considera essas transformações, é preciso sempre distinguir duas ordens de coisas. Há a transformação material das condições de produção econômica. Pode-se constatá-la conforme o espírito rigoroso das ciências naturais. Mas há também as formas jurídicas, políticas, religiosas, artísticas, filosóficas, em suma as formas ideológicas, pelas quais os homens tomam consciência desse conflito e o conduzem até o fim (Marx, 1965: 273; grifos meus).

A tradução possível dessa noção de "formas ideológicas" a fim de torná-la operacional poderia bem ser: sistemas de crenças historicamente determinados; ou visões de mundo inerentes aos 
agentes e grupos sociais; simbolismos políticos; ou ainda tradições culturais. A expressão "tradição" é uma boa chave de leitura para decifrar essa tripla mudança de interpretação: $i$ ) do sentido do conceito de ideologia (de inconsciência individual para consciência social), ii) do valor do conceito (de negativo para positivo) e iii) do domínio da ideologia (das representações para os comportamentos).

A conhecida passagem de Marx que abre o seu 18 Brumário- "A tradição de todas as gerações mortas pesa como um pesadelo sobre o cérebro dos vivos" (Marx, 1994: 437) - é certamente uma antecipação e um exemplo da concepção de ideologia referida por Gramsci e presente no Prefácio da Crítica da Economia Política. Essa passagem já sugere sua assimilação não à ideia arquitetônica do todo social e dos seus espaços característicos - infraestrutura e superestrutura - onde residiria a ideologia, nem à concepção puramente filosófica que opõe a "consciência social" falsificada ao "ser social" real. 0 que está em jogo aqui, e que será desenvolvido em todo o livro sobre o golpe de Estado de 1852, é muito mais um juízo sociológico sobre o valor prático e a eficácia social das ideias. Voltarei a esse ponto logo adiante a fim de aprofundar a análise da noção de "tradição" como ideologia.

0 último Engels retomou a questão do papel da ideologia e da configuração do campo ideológico quase da mesma maneira e nos mesmos termos pensados por Marx na década de 1850, expondo mais explicitamente, porém, as duas variáveis fundamentais dessa equação. Ele destacou o problema de um espaço próprio para as ideias e levantou a questão de sua eficácia social em termos mais evidentes, ainda que de maneira metafórica.

Em Engels, as ideologias políticas, tal como se manifestam em disputas a princípio muito abstratas ou retóricas entre "regimes de governo" (democracia, aristocracia, monarquia), deixam de ser "apenas as formas ilusórias" onde se desenvolvem as lutas efetivas entre as classes (Marx e Engels, 1982: 1.064), para tornarem-se modos efetivos de percepção social (esse é,afinal,o aspecto gnosiológico da expressão "pelas quais os homens tomam consciência" etc. notado por Gramsci) e o lugar onde são travadas e em torno dos quais são travadas as lutas sociais.

No processo histórico, Engels argumentou, as "formas políticas" que as lutas de classes assumem (Constituições, códigos jurídicos, sistemas políticos, teorias políticas, doutrinas filosóficas, etc.), essas cristalizações da "consciência social", são fatores senão determinantes, preponderantes para o andamento e para o entendimento do mundo social (Engels, 1979a, vol. 3: 284). A fim de completar a ideia, Engels também escreveu que "as condições políticas e mesmo a tradição" 
ideológica, ou seja, as configurações da consciência social "que perambulam como um duende no cérebro dos homens, também desempenham seu papel" condicionante na prática social (Engels 1979a, vol. 3: 284 e 285) .

Tomemos mais detidamente a noção de "tradição". A expressão, tal como aparece em Marx, parece útil para destacar o novo valor e a nova utilidade do conceito de ideologia nos clássicos do marxismo.

As passagens do 18 Brumário comentadas a seguir são mais sugestivas que explicativas desse problema e embora não valham, naturalmente, por uma teoria completa da ideologia, funcionam para ilustrar o sentido ativo das ideias (mas não seu papel independente e sua irredutibilidade ao social, diferença essencial nesse sistema de pensamento).

No esboço de análise da formação ideológica na França de meados do XIX, Marx destacouem seu comentário sobre vitória de Luís Bonaparte nas eleições presidenciais a função política da memória social:

A tradição histórica fez nascer nos camponeses franceses a crença no milagre de que um homem chamado Napoleão restituiria a eles toda a glória. E surgiu um indivíduo que se faz passar por esse homem porque carrega o nome de Napoleão. [...] A ideia fixa do sobrinho [de tomar para si todo o poder político] realizou-se porque ela coincidia com a ideia fixa da classe mais numerosa da França (Marx, 1994: 533; grifos meus).

Nessa passagem, "ideia fixa" na segunda menção a ela é a expressão substitutiva da palavra "ideologia". O peso da tradição ou as formas históricas da consciência social - o "duende" de Engels, para recordar a metáfora - terminaram por criar uma disposição subjetiva indestrutível na classe dos camponeses, cujo efeito prático consistiu em trocar, nas eleições de 1850, o sobrinho pelo tio, ou mais propriamente, o sobrinho-candidato pela imagem mitificada do tio, o Imperador de todos os franceses.

É certo que a relação entre a realidade política (Luís Napoleão) e a representação dessa realidade (Napoleão Bonaparte) se realiza de maneira complexa. Toda a terminologia empregada por Marx nesse livro para designar as ideias e sua função política como ideologias conservadoras ou transformadoras - 'frases', 'palavras de ordem', 'linguagens', 'idioma', 'trajes', 'máscara', 'tradições', 'ilusões', etc. - é sintomática de um novo problema pensado num novo registro: como

4 Para a questão da eficácia histórica da ideologia, v. também Engels, 1979b, vol. 3 : 294. 
interpelar, de um ponto de vista materialista, o simbolismo político, as ideologias, a tradição, enfim, e seu papel ativo na tradução dos interesses sociais através da sua linguagem própria?

Um dos primeiros problemas teóricos que derivam da análise histórica de Marx da II República na França é o problema da representação ideológica da realidade através dos simbolismos políticos. Ele é um meio possível para entendero simbolismo como ideologia e sua função social.

No quadro a seguir selecionei algumas passagens da primeira seção de 018 Brumário de Marx a fim de enfatizar duas ideias correlatas: o papel do simbolismo político como ideologia e suas duas funções sociais, transformadora e conservadora. Todas as frases são literais.

Esquema 2. Representação ideológica da realidade através de simbolismos políticos

\begin{tabular}{|c|c|c|c|}
\hline $\begin{array}{c}\text { simbolismo como } \\
\text { ideologia (1) }\end{array}$ & $\begin{array}{c}\text { a função } \\
\text { transformadora } \\
\text { desse simbolismo }\end{array}$ & $\begin{array}{c}\text { simbolismo como } \\
\text { ideologia (2) }\end{array}$ & $\begin{array}{c}\text { a função } \\
\text { conservadora } \\
\text { desse simbolismo }\end{array}$ \\
\hline $\begin{array}{l}\text { As revoluções } \\
\text { anteriores [1688; } \\
\text { 1789] tiveram que } \\
\text { lançar mão de } \\
\text { recordações da } \\
\text { história antiga para } \\
\text { se iludirem quanto } \\
\text { ao próprio } \\
\text { conteúdo. } \\
\text { A ressurreição dos } \\
\text { mortos nessas } \\
\text { revoluções [inglesa, } \\
\text { francesa] tinha, } \\
\text { portanto, a } \\
\text { finalidade de } \\
\text { glorificar as novas } \\
\text { lutas e não a de } \\
\text { parodiar as } \\
\text { passadas; de } \\
\text { engrandecer na } \\
\text { imaginação a tarefa } \\
\text { a cumprir, e não de } \\
\text { fugir de sua solução } \\
\text { na realidade; de } \\
\text { encontrar } \\
\text { novamente o } \\
\text { espírito da }\end{array}$ & $\begin{array}{l}\text { Mas, por menos } \\
\text { heroica que se mostre } \\
\text { hoje esta sociedade, } \\
\text { foi não obstante } \\
\text { necessário heroísmo, } \\
\text { sacrifício, terror, } \\
\text { guerra civil e batalhas } \\
\text { de povos para torná- } \\
\text { la uma realidade. E } \\
\text { nas tradições } \\
\text { classicamente } \\
\text { austeras da } \\
\text { república romana, } \\
\text { seus gladiadores } \\
\text { encontraram os } \\
\text { ideais e as formas de } \\
\text { arte, as ilusões de } \\
\text { que necessitavam } \\
\text { para esconderem de } \\
\text { si próprios as } \\
\text { limitações } \\
\text { burguesas do } \\
\text { conteúdo de suas } \\
\text { lutas e manterem } \\
\text { seu entusiasmo no } \\
\text { alto nível da grande } \\
\text { tragédia histórica. }\end{array}$ & $\begin{array}{l}\text { a Revolução de } \\
1848 \text { não soube } \\
\text { fazer nada melhor } \\
\text { do que parodiar } \\
\text { ora 1789, ora a } \\
\text { tradição } \\
\text { revolucionária de } \\
\text { 1793-1795. } \\
\text { - Caussidière por } \\
\text { Danton; } \\
\text { - Louis Blanc por } \\
\text { Robespierre; } \\
\text { - a Montanha de } \\
\text { 1845-1851 pela } \\
\text { Montanha de 1793- } \\
\text { 1795; } \\
\text { - o sobrinho pelo } \\
\text { tio. } \\
\text { Os franceses, } \\
\text { enquanto } \\
\text { estiveram } \\
\text { empenhados em } \\
\text { uma revolução, não } \\
\text { podiam livrar-se da } \\
\text { memória de } \\
\text { Napoleão, como } \\
\text { provaram as }\end{array}$ & $\begin{array}{l}\text { Todo um povo que } \\
\text { pensava ter } \\
\text { comunicado a si } \\
\text { próprio um forte } \\
\text { impulso para diante, } \\
\text { por meio da } \\
\text { revolução, se } \\
\text { encontra de repente } \\
\text { trasladado a uma } \\
\text { época morta, e para } \\
\text { que não possa haver } \\
\text { sombra de dúvida } \\
\text { quanto ao } \\
\text { retrocesso, surgem } \\
\text { novamente as } \\
\text { velhas datas, o velho } \\
\text { calendário, os } \\
\text { velhos nomes, os } \\
\text { velhos éditos que já } \\
\text { se haviam tornado } \\
\text { assunto de erudição } \\
\text { de antiquário, e os } \\
\text { velhos esbirros da } \\
\text { lei que há muito } \\
\text { pareciam defeitos } \\
\text { na poeira dos } \\
\text { tempos. }\end{array}$ \\
\hline $\begin{array}{l}\text { revolução e não de } \\
\text { fazer o seu espectro }\end{array}$ & $\begin{array}{c}\text { ideologia e } \\
\text { revolução social }\end{array}$ & $\begin{array}{l}\text { eleições de } 10 \text { de } \\
\text { dezembro. Diante }\end{array}$ & $\begin{array}{c}\text { ideologia e } \\
\text { reprodução social }\end{array}$ \\
\hline
\end{tabular}


caminhar outra vez. Lutero adotou a máscara do apóstolo Paulo, a Revolução de 17891814 vestiu-se alternadamente como a república romana e como o império romano. Camile Desmoulins, Danton,

Robespierre, SaintJust, Napoleão, os heróis, os partidos e as massas da velha Revolução Francesa, desempenharam a tarefa de sua época, a tarefa de libertar e instaurar a moderna sociedade burguesa, em trajes romanos e com frases romanas.

Cromwell e o povo inglês haviam tomado emprestado a linguagem, as paixões e as ilusões do Velho Testamento para sua revolução burguesa. A sociedade burguesa, com seu sóbrio realismo, havia gerado seus verdadeiros intérpretes e portavozes nos Says, Cousins, RoyerCoilards, Benjamm Constants e Guizots.
A revolução social do século XIX não pode tirar sua poesia do passado, e sim do futuro. Não pode iniciar sua tarefa enquanto não se despojar de toda veneração supersticiosa do passado. [...] A fim de alcançar seu próprio conteúdo, a revolução do século XIX deve deixar que os mortos enterrem seus mortos. dos perigos da revolução, ansiavam por voltar à abundância do Egito; e o 2 de dezembro de 1851 foi a resposta. Não só fizeram a caricatura do velho Napoleão, como geraram 0 próprio velho Napoleão caricaturado, tal como deve aparecer necessariamente em meados do século XIX. De 1848 a 1851 o fantasma da velha revolução anda em todos os cantos: desde Marrast, o républicain en gantsjaunes, que se disfarça no velho Bailly, até o aventureiro de aspecto vulgar $\mathrm{e}$ repulsivo que se oculta sob a férrea máscara mortuária de Napoleão.
Uma vez

estabelecida a nova formação social, os colossos antediluvianos desapareceram, e com eles a Roma ressurrecta - os Brutus, os Gracos, os Publícolas, os tribunos.os senadores e 0 próprio César. Uma vez alcançado o objetivo real, uma vez realizada a transformação burguesa da sociedade inglesa, Locke suplantou Habacuc.

Fonte: trechos selecionados extraídos de 018 Brumário de Luís Bonaparte, de Marx (1994).

Como se vê, o mundo das ideias - o ideológico, em sentido lato- não é simplesmente uma forma mistificadora da realidade social. Ainda que "a linguagem, as paixões e as ilusões" possam cumprir essa função de "máscara" ou disfarce ("trajes"), escondendo dos próprios 
protagonistas o conteúdo real, ou os objetivos históricos, das suas batalhas, há mesmo uma dimensão positiva dos simbolismos políticos. Os "ideais e as formas de arte, as ilusões", ainda que falsos em si mesmos, quando confrontados com a realidade, são essenciais para "manterem" o "entusiasmo" dos protagonistas do drama "no alto nível da grande tragédia histórica". Talvez por isso mesmo, uma das tarefas da revolução social anticapitalista seja produzir uma nova "ideologia", isto é, um novo simbolismo que rompa com as antigas referências heroicas da revolução burguesa, essa "veneração supersticiosa do passado".

Por outro lado, a função conservadora dos simbolismos ideológicos não pode ser menosprezada. A projeção da figura heroica do tio na figura farsesca do sobrinho, uma paródia no sentido próprio do termo, sucedida por outras tantas ("Caussidière por Danton, Louis Blanc por Robespierre", etc.), só pode se realizar plenamente porque o real se "disfarça" e se "oculta" sob essas projeções mistificadoras. Essa é a senha para voltar a História para trás: não há "sombra de dúvida quanto ao retrocesso" político que o golpe de estado de dezembro de 1851 representou, não há sombra de dúvida quanto à derrota social que o fracasso dos socialistas e socialdemocratas 1848 representou. A partir de então, toda a simbologia revolucionária - o arremedo da Roma Antiga e a imitação da Revolução de 1789 - podem desaparecer e serem substituídas por outra formação ideológica, sintonizada com o espírito do capitalismo ("Locke suplantou Habacuc").

O que é, então, a ideologia para os clássicos do marxismo?

A ideologia é uma estrutura e uma prática. A ideologia não é um estado subjetivo da consciência (imaginação), nem um produto derivado de outras instâncias (um mero "efeito", como na expressão consagrada por Poulantzas (1971)), mas uma estrutura do mundo social (uma "realidade"). E a expressão "estrutura ideológica" designa o terreno onde certas práticas sociais simbólicas se dão. 0 fundamental é que essas práticas têm aí a mesma materialidade que as ações e os conflitos nos demais domínios do mundo social. E é através da ideologia (ou das "formas ideológicas" para falar como Marx, ou da "tradição", para falar como Marx e Engels) que os agentes sociais conhecem e se reconhecem (onde os homens "tomam consciência desses conflitos" etc.), isto é, situam-se em relação ao espaço social, e situam os outros agentes no espaço social. Daí o seu sentido positivo e produtivo e o seu "valor gnosiológico", como enfatizou Gramsci, na mesma linha dessa passagem de Marx: "E nas tradições classicamente austeras da república romana, seus gladiadores encontraram os ideais e as formas de arte, as ilusões de que necessitavam para esconderem de 
si próprios as limitações burguesas do conteúdo de suas lutas e manterem seu entusiasmo no alto nível da grande tragédia histórica" (Marx, 1994: 439).

A ideologia é assim uma visão ou uma concepção social específica do mundo social, nem falsa, nem verdadeira em si mesma, isto é, correspondente ou não aos fatos da realidade objetiva, ainda que sua gramática, sua forma de arranjar as ideias, possa conter elementos falsos ou elementos verdadeiros, constatações de fato e juízos de valor. A medida para julgar as tradições ideológicas passa então a ser funcional, e não psicológica (já que se trata de um fenômeno social, não individual) e menos ainda intelectual (concepções certas ou erradas em si mesmas). Ou a ideologia é eficaz - como instância de produção, reprodução e transformação da vida social - ou não é. Nunca pode ser, portanto, uma ideia fora do lugar. Daí a função transformadora ou conservadora dos simbolismos ideológicos, como referido no 18 Brumário de Marx.

\section{As tradições ideológicas e seus mecanismos sociais}

Nesse nível de abstração, como então conceber e explicar as tradições ideológicas? Quais são seus suportes? Qual é sua função social? Como elas operam? Por quais mecanismos - materiais, sociais e simbólicos - elas atuam?

Mesmo se ficarmos numa definição genérica dos efeitos das tradições ideológicas dominantes, deveria ser possível listar ao menos sete manifestações desse fenômeno social e associar a ele outras tantas funções ligadas a questões relativas a conflitos de interesses e a disputas pelo poder político numa formação social.

Entendidas como um conjunto de significados e valores que colaboram com ou legitimam a dominação social, as formas ou tradições ideológicas podem aparecer como: práticas significantes e processos simbólicos (num sentido muito próximo à ideia de "cultura"); ideias e crenças de uma classe ou grupo social (uma visão de mundo); um campo discursivo onde poderes sociais relevantes se enfrentam (através da retórica política); concepções ou suposições falsas e/ou distorcidas da realidade social (um discurso "ideológico" propriamente dito); um ideário, um pensamento organizado, como são os sistemas teóricos especulativos (isto é, uma doutrina); idiomas específicos com léxico próprio ("linguagens" sociais); palavras de ordem, slogans, lugares-comuns.

As tradições ideológicas, assim concebidas, podem, conforme Eagleton, unificar grupos ou classes, promovendo sua identidade social 
e/ou sua solidariedade política; orientar a ação política, providenciando a seus partidários motivos e também objetivos; promover interesses políticos relevantes em face de preferências opostas; racionalizar ou oferecer explicações e justificações logicamente coerentes para interesses ou comportamentos sociais controversos; universalizar, em nome de "conceitos dominantes" (a expressão é de Marx e Engels), interesses particulares (de época, lugar, classe) como interesses comuns a fim de torná-los socialmente aceitáveis; e naturalizar crenças e valores específicos, convertendo-os em senso comum, em realidades inevitáveis, em verdades anônimas e universais 5 .

Em meio a essa extensa lista de funções das "formas ideológicas" (Marx), tomemos dois pontos que quase nunca aparecem para ilustrar e ampliar essa discussão.

Normalmente, análises do funcionamento concreto e das operações teóricas da ideologia estão vinculadas a duas operações padrão desse fenômeno social: sua capacidade de ocultar interesses e sua propriedade para universalizar valores específicos. Quero destacar, contudo, dois outros fenômenos. Eles estão ligados: $i$ ) à capacidade unificadora da ideologia dominante (portanto, à sua função política); e ii) à própria unidade de uma ideologia politicamente dominante para realizar essa função, (portanto, à sua natureza específica, sua morfologia como retórica, discurso, doutrina, linguagem etc.). Essa unidade do discurso político-ideológico implica outros dois problemas: (a) sua uniformidade interna (isto é, sua lógica como sistema simbólico, como uma "tradição"); e (b) sua predominância numa formação social onde competem outras ideologias políticas para se firmarem como universais (isto é, sua supremacia ou "hegemonia"). É sempre preciso explicitar a complexidade da topologia de um dado campo ideológico, seja porque o poder da ideologia política dominante para unificar discursos e práticas sociais nunca pode ser suposto antecipadamente (como um pressuposto da noção de ideologia), seja porque sua coerência interna é um objetivo a ser alcançado, não um ponto de partida. Voltarei a esse aspecto mais adiante.

Não é exagerado desconfiar que quanto mais uniforme, maior deve ser sua primazia e quanto mais favorita é uma ideologia, maior sua competência para impor e soldar interesses de todo tipo (de grupo, de classe etc.). Mesmo o problema da função agregadora da ideologia pode ser pensado a partir de duas perspectivas: $(a)$ a da coesão social, onde é mais conveniente manter a expressão "ideologia dominante"; e $(b)$ da

\footnotetext{
${ }^{5}$ Ver, para essa lista de tarefas, Eagleton, 1997: 50-64 e passim.
} 
integração moral, da unidade psicológica, enfim, da solidariedade dos grupos sociais. No caso da solidariedade entre grupos de elite, para marcar a diferença, seria mais conveniente dizer "ideologia dirigente". Logo, para efeito de análise, é útil distinguir a função da ideologia que decorre de uma perspectiva mais estrutural - a reprodução social - da função que decorre de uma perspectiva mais histórica - por exemplo, a unificação política das classes dirigentes. Se a expressão "ideologia burguesa" recobre ainda que de modo inespecífico a demanda da reprodução social, é preciso atentar para a existência de uma série de ideologias particulares (econômicas, políticas, jurídicas, morais, estéticas, teóricas, etc.) que entram em questão quando se pensa no problema da unidade da classe dirigente e na garantia da sua supremacia social6.

É possível supor que os mesmos mecanismos ideológicos ou técnicas de "construção simbólica" (Thompson, 1995), referidos acima, tais como racionalização, universalização, dissimulação, naturalização, etc., atuem tanto nos processos de dominação social quanto nos processos de unificação das classes dirigentes, mas esses mecanismos não mobilizam necessariamente nem os mesmos elementos ideológicos, nem a mesma maneira de combiná-los. Isso porque há uma diferença e uma desproporção entre as ideologias economicamente dominantes (ou ideologias "globais") e as várias ideologias politicamente dirigentes ${ }^{7}$. Depois porque uma e outra nunca são uniformes (isto é, sem contradições internas), unitárias (isto é, plenas,

\footnotetext{
6 Isso é mais típico em períodos de transição social ou de transformação das estruturas de dominação. Quando se toma o Brasil dos anos 1920 a 1940, isso é bem saliente. Assim, por exemplo, a doutrina Góis foi a cobertura programática para a nova política do Exército nacional em nome de sua grandeza, poder e, em especial, do monopólio dos meios de violência; o industrialismo (bem antes do desenvolvimentismo) foi a senha para a ascensão da fração industrial, abrigada sob o "pensamento econômico" de Roberto Simonsen; o nacionalismo foi uma disposição ao mesmo tempo estética e política dos intelectuais; o estatismo foi a divisa do tenentismo radical em nome de um Estado centralizador e intervencionista (promotor do "desenvolvimento" e da "independência" nacionais); o tecnocratismo foi a justificativa ideológica para a superioridade política da burocracia de Estado e para sua pretensão de monopolizar a iniciativa política e o poder governamental; e o trabalhismo, a bandeira da integração política da classe operária e da incorporação das questões sociais pelo "Estado nacional".

7 Em princípios do século XX, o liberalismo político (devidamente aclimatado às condições nacionais) poderia ser a ideologia da classe política, mas, segundo Warren Dean, não a da classe dominante: "o liberalismo, de um modo geral, não exerceu muita influência entre os industriais paulistas durante as décadas de 1920 e 1930". Prova disso é que já na "década de 1920 começa-se a encontrar, no seio da elite [econômica] de São Paulo, mas principalmente entre os industriais, um robusto interesse pelas variedades do fascismo europeu". Segundo Dean, uma das razões da implicância dos líderes da indústria com o liberalismo político clássico é que ele "fomentava a confusão dos políticos profissionais" (Dean, s.d.: 184).
} 
acabadas, "totais") e homogêneas (sem camadas diferentes ou ainda que com camadas dessemelhantes, perfeitamente sobrepostas ou hierarquizadas). Sempre podem ocorrer empréstimos entre visões de mundo distintas, ainda que seus discursos, linguagens ou doutrinas possam se definir como "anti" isso ou aquilo. Como resumiu Terry Eagleton,

As ideologias são, de modo geral, formações diferenciadas, complexas internamente, com conflitos entre seus vários elementos que precisam ser continuamente renegociados e resolvidos. [...] Se as ideologias não são tão 'puras' e unitárias quanto elas próprias gostariam de acreditar, isso ocorre porque, em parte, existem somente em relação a outras ideologias. [...] Martin Seliger [...] argumenta que as ideologias são, tipicamente, misturas de enunciados analíticos e descritivos, de um lado, e prescrições morais e técnicas, de outro [...]. Estudar uma formação ideológica é, portanto, entre outras coisas, examinar o complexo conjunto de ligações ou mediações entre seus níveis mais e menos articulados (Eagleton, 1997: 51, 53 e 55; grifos meus).

No mesmo sentido, o universo ideológico onde elas se movem, nascem e morrem é um universo bastante complexo, hierarquizado, desigual e contraditório. Como Williams (1977) argumentou, há aí, ao mesmo tempo, "formas de consciência" dominantes, ideias historicamente residuais e formações ideológicas emergentes. Assim, nesse espaço social podem conviver diversas ideologias políticas (como no Brasil nos anos 1930, por exemplo: liberalismo, autoritarismo, corporativismo). Elas são produzidas e garantidas por aparelhos ou instituições diferentes (partidos, sindicatos, movimentos, organizações e mesmo o próprio Estado), e são, em geral, elaboradas e difundidas por uma intelligentsia. Frequentemente há uma hierarquia instável entre as ideologias e entre os produtores de ideologias (os intelectuais), uma vez que a disputa nesse mundo não se dá somente em torno de conteúdos e proposições livrescas, mas em torno de posições de poder efetivo. As relações políticas nesse domínio, tanto entre ideias como entre ideólogos, poderiam ser descritas como relações de colaboração, convergência, concorrência, conflito etc. $\mathrm{Ou}$ por analogia com as relações da teoriados conjuntos: inclusão, reunião, interseção, diferença, complemento, equivalência e todas aquelas propriedades que decorrem delas.

Williams recomendou ainda que toda análise histórica das formações e das tradições ideológicas deveria procurar apreender as relações dinâmicas no interior dos "processos culturais", isto é, dos

\footnotetext{
80 livro de Seliger citado é o Ideology and Politics (1976).
} 
processos de produção de práticas e experiências culturais, significados e valores simbólicos, não em termos de fases e etapas, ou de variações evolutivas de uma cultura ou ideologia dominante segundo o esquema de primeiro isso, depois aquilo. Mas como uma "inter-relação dinâmica de elementos variáveis e variados historicamente em cada ponto desses processos", onde sempre se enfrentam e se chocam "movimentos e tendências" culturais, noções, formações e concepções diferentes, cada uma com um grau específico de eficácia social (1977, p. 121-122).

Esses seriam assim alguns dos pré-requisitos teóricos e metodológicos - um modelo de aplicação, por assim dizer - para produzir um mapa das ideologias de uma formação social específica num período determinado do seu desenvolvimento histórico. Esse mapa deveria não apenas descrever a topologia de um dado campo ideológico, suas hierarquias e subordinações, mas demonstrar como, quando e por que uma dada forma ideológicase tornou a ideologia dirigentee o seu discurso,o dominante.

\section{Conclusões}

$\mathrm{Na}$ primeira parte deste ensaio fiz um relato da gênese e da trajetória do conceito de ideologia no pensamento social. Ele foi útil não só para expor os diferentes sentidos que o termo adquiriu, mas para datar suas sucessivas torções de significado. Em seguida, procurei demonstrar que, mesmo para os clássicos do marxismo, "ideologia" é uma noção teórica que deveria ser entendida de maneira mais exigente do que pretendem os resumos usuais sobre esse assunto. Processos ideológicos são processos de formação da realidade e não meras projeções imperfeitas ("efeitos invertidos") ou erradas ("falsas") do mundo social. Poderíamos chamar esse sentido do conceito de ideologia de performativo. Esses processos podem ser mais que mediações enganadoras ("máscaras") entre a consciência dos agentes e o mundo social, ainda que se possa encontrar a confirmação de todas essas acepções nos próprios Marx e Engels, já que foram mudando seu entendimento ao longo do tempo e, assim, sobre o que "ideologia", termo pouco frequente depois de $A$ ideologia alemã, deveria designar. 0 quadro construído com algumas passagens de 018 Brumário de Luís Bonaparte sobre a representação ideológica da realidade através dos vários simbolismos políticos mobilizados na Revolução de 1848 (os romanos, os revolucionários franceses, Napoleão, etc.), funciona para ilustrar como todas essas significações convivem para descrever, de modo complexo, uma realidade simbólica complexa. 
Nesse contexto, a virada mais importante, como sublinhei, foi a transfiguração, operada nessa corrente intelectual, da valência do conceito de ideologia (do negativo ao positivo) e da realidade que ele deve descrever (de fenômeno puramente mental para "estrutura material"), já que essa nova acepção permite entender a prática ideológica como prática social, e não como um fenômeno da consciência. Ele deve muito a Gramsci. A ideologia é um mecanismo de sujeição social ("reprodução") que precisa recorrer a instituições específicas ou, na sua linguagem, a "aparelhos". A ideologia somente existe como força social através dos "aparelhos ideológicos de Estado". O famoso ensaio de Althusser (1976) estabeleceu que o sistema escolar, o sistema jurídico, o sistema político, as religiões, a família e a escola são instituições cuja função é rotinizar valores e ideias dominantes, definindo as práticas dos agentes sociais como práticas destinadas à reiteração das relações de dominação em dada sociedade.

Propus então neste texto que essas operações semânticas poderiam ser apreendidas pela noção, bastante plástica e operacional, de "tradição", tal como já pensada por Engels e Marx e sempre referida de modo alusivo e incidental. Todavia, a "tradição [...] que perambula como um duende no cérebro dos homens", como dirá Engels, sintetiza várias propriedades importantes do conceito de ideologia. Quando Marx escreve que "A tradição histórica fez nascer nos camponeses franceses a crença no milagre de que um homem chamado Napoleão restituiria a eles toda a glória", ele está indicando que esse fenômeno da percepção ideológica possui um valor tanto negativo quanto positivo (performativo), que ele ultrapassa a inconsciência individual para transformar-se em consciência social (uma tradição compartilhada), e que supera o domínio puro das representações simbólicas para definir os comportamentos políticos.

Por último, procurei estabelecer alguns parâmetros gerais para analisar as operações da ideologia - das "formas ideológicas" - a partir de dois aspectos que me parecem fundamentais para entender a dimensão política das ideologias políticas: seu papel unificador e sua unidade interna.

Tradições ideológicas cumprem duas funções básicas: ocultar interesses específicos (de classe, de grupo, de categorias sociais, etc.) e universalizar ideias particulares. 0 que eu procurei ressaltar nesse ensaio é que isso depende da capacidade da ideologia dominante de unificar interesses em disputa; e que essa capacidade depende, por sua vez, da própria unidade da ideologia dominante para realizar essa função em uma dada sociedade. Todavia, a própria "unidade da ideologia dominante" deve supor sua uniformidade interna (isto é, sua 
relativa coerência como sistema simbólico) e seu poder para se impor como a forma ideológica hegemônica numa sociedade onde competem várias ideologias, tradições, concepções, visões de mundo. Esse problema é tanto mais complexo quando se considera a existência, ao mesmo tempo, de uma ideologia dominante, isto é, de uma ideologia cuja função é a integração global de uma dada sociedade ("coesão social"), e de uma ideologia dirigente, uma formação de ideias cuja função é garantir a solidariedade entre grupos de elite ("unidade política"). Cada uma delas não mobiliza nem os mesmos elementos simbólicos, nem a mesma maneira de combiná-los. Para retomar a sugestão de Marx na sua análise sobre o período 1848-1951, é como se a veneração à figura de Napoleão cumprisse a primeira função (união da sociedade francesa em torno de uma ideia-força mítica) e a evocação da grande Revolução, a segunda função: soldar ideologicamente as classes dirigentes. É nesse sentido que pode ser lida a frase de Marx: "a Revolução de 1848 não soube fazer nada melhor do que parodiar ora 1789, ora a tradição revolucionária de 1793-1795" (Marx, 1994: 438).

\section{Referências}

ABERCROMBIE, Nicholas; HILL, Stephen; and TURNER, Bryan S. The Dominant Ideology Thesis. London: Allen \& Unwin. 1984.

ALTHUSSER, Louis. Idéologie et appareils idéologiques d'État. (Notes pour une recherche). In: . Positions (1964-1975). Paris: Les Éditionssociales, p. 67-125. 1976.

BELL, Daniel. 0 fim da ideologia. Brasília: Editora Universidade de Brasília. 1980.

BENDIX, Reinhard. Ideologia. In: Outhwaite, William e Bottomore, Tom (orgs.), Dicionário do pensamento social do século XX. Rio de Janeiro: Jorge Zahar. 1996.

BOBBIO, Norberto. Ensaio sobre ciência política na Itália. Brasília: Editora Universidade de Brasília; São Paulo: Imprensa Oficial do Estado. 2002.

CODATO, Adriano. Elites e instituições no Brasil: uma análise contextual do Estado Novo. Tese (Doutorado em Ciência Política). Universidade Estadual de Campinas - Unicamp. 2008.

DEAN, Waren. A industrialização de São Paulo (1880-1945). 3ạ. ed. São Paulo: Difel.s.d.

EAGLETON, Terry. Ideologia: uma introdução. São Paulo: Editora UNESP; Boitempo. 1997. 
ENGELS, Friedrich. Carta de Engels a Bloch, 21-22 set. 1890. In: Karl Marx e Friedrich Engels, Obras escolhidas. São Paulo: Alfa-Omega, vol. 3. 1979 a.

ENGELS, Friedrich. Carta de Engels a Mehring, 14 jul. 1893 In: Karl Marx e Friedrich Engels, Obras escolhidas. São Paulo: Alfa-Omega, vol. 3. 1979b.

GEUSS, Raymond. The Idea of a Critical Theory: Habermas and the Frankfurt School. Cambridge: Cambridge University Press. 1981.

GRAMSCI, Antonio. Quaderni del Carcere. Edição crítica do Instituto Gramsci. Valentino Gerratana (org.). Torino: Einaudi. 1977.

GRAMSCI, Antonio. Obras escolhidas. São Paulo: Martins Fontes.1978.

KNIGHT, Kathleen. Transformations of the Concept of Ideology in the Twentieth Century. The American Political Science Review, vol. 100, n. 4: 619-626. 2006.

LARRAIN, J. Ideologia. Tom Bottomore (org.), Dicionário do pensamento marxista. Rio de Janeiro: Jorge Zahar. 1988.

LOSSO, Tiago Bahia. Estado Novo: discurso, instituições e práticas administrativas. Tese (Doutorado em Ciências Sociais). Universidade Estadual de Campinas. Campinas (SP). 2006.

LYOTARD, Jean-François. La Condition postmoderne: rapport sur le savoir. Paris: Minuit. 1979.

MARX, Karl e ENGELS, F. L'ideologie allemande («Conception matérialiste et critique du monde »). In: Karl Marx, OEuvres. Éd. établie par Maximilien Rubel. Paris: Gallimard, vol. III: Philosophie. 1982.

MARX, Karl. Critique de l'Économie Politique. In: OEuvres. Éd. établie par Maximilien Rubel. Paris: Gallimard, vol. I: Économie. 1965.

MARX, Karl. Le 18 Brumaire de Louis Bonaparte. In: OEuvres. Éd. établie par Maximilien Rubel. Paris: Gallimard, 1994, vol. IV, Tomo I: Politique.

MULLINS, Willard A. On the Concept of Ideology in Political Science. The American Political Science Review, vol. 66, n. 2: 498-510. 1972.

POULANTZAS, Nicos. Pouvoir politique et classes sociales. Paris: Maspero. 1971.

SELIGER, Martin. Ideology and Politics. New York: Free Press. 1976.

SILVA, Ricardo. A ideologia do Estado autoritário no Brasil. Chapecó/SC: Argos. 2004. 
SOARES, Gláucio Ary Dillon. Ascensão e queda do marxismo: os dados que saem dos livros. Insight Inteligência, v. 15, n. 59, p. 54-62. 2013.

THOMPSON, John B. Ideologia e cultura moderna: teoria social crítica na era dos meios de comunicação de massa. 2ª ${ }^{\mathrm{a}}$.ed. Petrópolis: Vozes. 1995.

WILLIAMS, Raymond. Marxism and Literature. Oxford/New York: Oxford University Press.1977.

WILliAMS, Raymond. Palavras-chave: um vocabulário de cultura e sociedade. São Paulo: Boitempo. 2007.

Recebido em 02 de março de 2016

Aprovado em 10 de abril 2016

\title{
The concept of ideology in classical Marxism: a review and an application model
}

\begin{abstract}
The purpose of this essay is to unveil some operational aspects of the theoretical notion of "ideology" as conceived by the Marxist tradition in order to emphasize its usefulness in social analysis. The argument to be defended here is that, either updated or not according to academic fashions, this term still works properly as long as it is understood in its full meaning. I then show how the transfiguration of the concept's meaning (from a negative to a positive sense) and the reality it describes (from a purely mental phenomenon to a material structure) allows us to understand ideological practice as social practice, and how all this comes caught up by the notion of "tradition" as conceived by Marx and Engels. Then, I enumerate some theoretical and methodological requirements to produce a map of ideologies in a particular social formation. This map should serve not only to describe the topology of a given ideological field, but also to demonstrate how, when and why a particular ideology became the official ideology and its discourse, the dominant discourse.
\end{abstract}

Keywords: ideology, Marxism, ruling ideologies, social theory, social analysis. 